\title{
Expression profiling of genes regulated by sphingosine kinase1 signaling in a murine model of hyperoxia induced neonatal bronchopulmonary dysplasia
}

Viswanathan Natarajan 1,2,3, Alison W. Ha ${ }^{1}$, Yangbasai Dong ${ }^{1}$, Narsa M. Reddy², David L. Ebenezer ${ }^{3}$, Prasad Kanteti ${ }^{2}$, Sekhar P. Reddy ${ }^{1}$, J. Usha Raj ${ }^{1}$, Zhengdeng Lei ${ }^{4}$, Mark Maienschein-Cline ${ }^{4}$, Zarema Arbieva ${ }^{5}$ and Anantha Harijith ${ }^{2,6^{*}}$ (D)

\begin{abstract}
Background: Sphingosine- 1-Phosphate (S1P) is a bioactive lipid and an intracellular as well as an extracellular signaling molecule. S1P ligand specifically binds to five related cell surface G-protein-coupled receptors (S1P 1-5 $_{\text {- }}$ ). S1P levels are tightly regulated by its synthesis catalyzed by sphingosine kinases (SphKs) 1 \& 2 and catabolism by S1P phosphatases, lipid phosphate phosphatases and S1P lyase. We previously reported that knock down of SphK1 (Sphk $1^{-1}$ ) in a neonatal mouse BPD model conferred significant protection against hyperoxia induced lung injury. To better understand the underlying molecular mechanisms, genome-wide gene expression profiling was performed on mouse lung tissue using Affymetrix MoGene 2.0 array.

Results: Two-way ANOVA analysis was performed and differentially expressed genes under hyperoxia were identified using Sphk1 $1^{-1-}$ mice and their wild type (WT) equivalents. Pathway (PW) enrichment analyses identified several signaling pathways that are likely to play a key role in hyperoxia induced lung injury in the neonates. These included signaling pathways that were anticipated such as those involved in lipid signaling, cell cycle regulation, DNA damage/apoptosis, inflammation/immune response, and cell adhesion/extracellular matrix (ECM) remodeling. We noted hyperoxia induced downregulation of the expression of genes related to mitotic spindle formation in the WT which was not observed in Sphk $1^{-1-}$ neonates. Our data clearly suggests a role for SphK1 in neonatal hyperoxic lung injury through elevated inflammation and apoptosis in lung tissue. Further, validation by RT-PCR on 24 differentially expressed genes showed $83 \%$ concordance both in terms of fold change and vectorial changes. Our findings are in agreement with previously reported human BPD microarray data and completely support our published in vivo findings. In addition, the data also revealed a significant role for additional unanticipitated signaling pathways involving Wht and GADD45.
\end{abstract}

Conclusion: Using SphK1 knockout mice and differential gene expression analysis, we have shown here that S1P/SphK1 signaling plays a key role in promoting hyperoxia induced DNA damage, inflammation, apoptosis and ECM remodeling in neonatal lungs. It also appears to suppress pro-survival cellular responses involved in normal lung development. We therefore propose SphK1 as a therapeutic target for the development drugs to combat BPD.

Keywords: Sphingosine kinase 1, Sphingosine 1 phosphate, Oxidative stress, Lipid signaling, Neonatal lung injury

\footnotetext{
* Correspondence: harijith@uic.edu

${ }^{2}$ Department of Pharmacology, University of Illinois, Chicago, IL 60612, USA

${ }^{6}$ Department of Pediatrics, University of Illinois, Room \# 3140, COMRB

Building, 909, South Wolcott Avenue, Chicago, IL 60612, USA

Full list of author information is available at the end of the article
} 


\section{Background}

Bronchopulmonary dysplasia (BPD) is a chronic condition affecting up to $25 \%$ of extreme preterm newborn infants $[1,2]$. It is characterized by alveolar simplification, leading to loss of gas exchange area and a decline in lung function that worsens with age [3]. Advances in the care of preterm newborn such as ventilation support has increased the survival rates, however, the practice has also elevated the prevalence of BPD [1]. Though BPD is of multifactorial in origin, exposure to hyperoxia is one of the major contributing factors $[4,5]$. There is a preponderance of evidence in support of a role for reactive oxygen species (ROS) induced lung injury in the development of BPD [6].

$\mathrm{S} 1 \mathrm{P}$ is a signaling bioactive lipid mediator, generated by phosphorylation of sphingosine catalyzed by two intracellular sphingosine kinases (SphKs) 1 \& 2. S1P is transported outside the cell either by ATP binding cassette $(\mathrm{ABC})$ or Spns2 transporter where it exerts its effects through five types of cell surface G-proteincoupled S1P receptors $1-5\left(\mathrm{~S}_{\mathrm{PR}} \mathrm{P}_{1-5}\right)$. The pleotropic effects of S1P depend on the pathophysiology and the type of $\mathrm{S} 1 \mathrm{P}$ receptor it binds to [7]. S1P is protective in the sepsis model whereas it plays a detrimental role in hyperoxic lung injury and asthma [8]. In lung pathologies such as asthma [8], pulmonary fibrosis [9] and pulmonary hypertension $[10,11]$, genetic deletion of Sphk1 or inhibition of SphK1 activity with small molecule inhibitors conferred significant protection from airway/lung inflammation and injury. However, in sepsis-induced lung injury, infusion of S1P protected the animals from lung injury and pulmonary edema by enhancing endothelial barrier function [12]. Thus, S1P is a double edged sword as its action varies depending upon the agent inducing lung injury or the receptor through which it acts.

In our neonatal mouse model of BPD, we showed that hyperoxia increased the expression of SphK1, but not SphK2, leading to increased synthesis of S1P [13]. Deletion of $S p h k 1$, but not $S p h k 2$ gene resulted in decreased $\mathrm{S} 1 \mathrm{P}$ levels in lungs accompanied by reduced expression of NADPH oxidase (Nox) 2 \& 4 and ROS, leading to amelioration of hyperoxia-induced lung injury. The role of SphK1/S1P on the expression of genes involved in lung inflammation, injury and repair is not clear. We therefore hypothesized that reduced inflammation and improved alveolarization observed in $\operatorname{Sph} k 1^{-/-}$mice resulted from differential regulation of genes, promoting normal course of lung development while suppressing injury.

To test this hypothesis and to identify the various mechanisms by which the Sphk1 $1^{-/-}$confers pulmonary protection, differential gene expression analysis in the lungs of $S p h k 1^{-/-}$mice before and after treatment with hyperoxia was compared to the Wild Type mice. The results suggest that SphK1/S1P signaling cascade mediates hyperoxia-induced lung injury by modulation of genes related to inflammation, apoptosis, immune responses and redox signaling in mouse lung. Our data also identifies SphK1 as a potential therapeutic target to combat BPD.

\section{Methods \\ Mouse model \\ Mouse experiments and animal care}

All experiments using animals were approved by the Institutional Animal Care and Use Committee at the University of Illinois at Chicago (protocol \# 15-240). We used male neonatal mice to study the effect of hyperoxia in the newborn developing lungs. The lung development in the neonatal mice at birth is in the late canalicular/early alveolar stage corresponding to that of a preterm human neonate at 24-26 weeks of gestation. Sphk $1^{-/-}$mice were obtained from Dr. Richard L. Proia (NIDDK, National Institutes of Health, Bethesda), and backcrossed to C57BL/6 background for two generations (F2 hybrid). The resultant mixed background of $\mathrm{C} 57 \mathrm{BL} / 6$ strain and the original background (F2 hybrid) was used as controls and is referred to hereafter as Wild Type (WT). The WT or Sphk $1^{-/-}$newborn (NB) mice along with the lactating dams were exposed to hyperoxia of $75 \% \mathrm{O}_{2}$ or normoxia from postnatal (PN) day 1 for 7 days as previously described [13]. NB mice (along with their mothers) were placed in cages in an airtight Plexiglas chamber $(55 \times 40 \times 50 \mathrm{~cm})$, maintained in hyperoxic condition. Two lactating dams were used. Mothers were alternated between hyperoxia and normoxia every $24 \mathrm{~h}$. The litter size was kept limited to 6 pups to control the effects of litter size on nutrition and growth. The animals were maintained as per the University of Illinois protocol for animal use. Oxygen levels were constantly monitored by an oxygen sensor that was connected to a relay switch incorporated into the oxygen supply circuit. The inside of the chamber was kept at atmospheric pressure. The animals were sacrificed and the lung tissues collected, homogenized and whole cell lysates prepared for further analysis, RNA isolation (superior lobe of right lung), and microarray studies.

\section{Sample processing and microarray based gene expression analyses}

We used MoGene 2.0 array (Thermo Fisher Scientific, Waltham, MA) that interrogates over 35 thousand mouse specific RefSeq transcripts and represents a comprehensive platform for the whole transcriptome expression profiling [14].

Lung tissue was perfused with PBS prior to harvesting from the animal, and processed immediately after 
harvesting. Total RNA was isolated from the whole lung tissue using microRNeasy ${ }^{\circ}$ kit (Qiagen, Maryland, Cat no. 74004). RNA samples derived from individual animals were separately labeled, hybridized, washed/stained and scanned according to the standard WT PLUS labeling protocol recommended by the manufacturer (Thermo Fisher Scientific, Waltham, MA). Three individual mouse lungs were collected for each of the four experimental groups.

\section{Data collection}

Collected hybridization signals were processed using Genomics Suite 6.6 statistical package (Partek, Inc., Saint Louis, MO). The following parameters were applied for hybridization signal processing: RMA algorithm based background correction, quantile normalization procedure, and probe set summarization [15].

All processed array files were inspected for the following quality metrics: average signal present, signal intensity of species-specific housekeeping genes, relative signal intensities of labeling controls, absolute signal intensities of hybridization controls, and across-array signal distribution plots [16]. All hybridizations passed quality control according to indicated labeling and hybridization controls.

\section{Identification of differentially expressed transcripts}

To identify a subset of genes reactive specifically to the hyperoxic environment depending on the status of Sphk1 gene, we performed a two-way ANOVA using the level of oxygen and status of Sphk1 as comparison factors. We

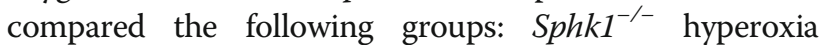
$\left(S p h k 1^{-/-} \mathrm{HO}\right), S p h k 1^{-/-}$normoxia $\left(S p h k 1^{-/-} \mathrm{RA}\right)$, Wild Type hyperoxia (WT HO) and Wild Type normoxia (WT RA). ANOVA model was based on Method of Moments [17] in combination with Fisher's Least Significant Difference (LSD) contrast (Tamhane and Dunlop, 2000). The latter allowed calculation of direction and magnitude of change for all pair-wise comparisons between the treatment groups, and was later validated by RT-PCR. Calculated raw $p$-values were corrected for False Discovery Rate (FDR) according to Benjamini-Hochberg (BH) correction procedure [18]. Differentially expressed transcripts were annotated according to Affymetrix NA35 Release of the NetAffx Analysis Center.

\section{Availability of data and materials}

The microarray datasets supporting the conclusions of this article are available in the the National Center for Biotechnology Information Gene Expression Omnibus repository, with unique persistent identifier of NCBI tracking system accession number: 18,084,823, and hyperlink to the datasets is given below.

https://www.ncbi.nlm.nih.gov/geo/query/acc.cgi?acc= GSE87350
Pathway enrichment analyses and data visualization We performed pathway enrichment analyses (EA) in order to understand the biological factors driving the protective effect observed in Sphk1 $1^{-/-}$mice with BPD. Transcripts identified as differentially expressed in $\mathrm{KO}$ animals in response to oxygen levels in two-way ANOVA test (FDR cut off of 0.05) were imported into MetaCore Genomic Analyses Tool Release 6.22 (Thomson Reuters) for analyses.

Differentials were analyzed using the "Pathway Maps" ontology and the top 50 most enriched pathways (PW) were identified. The output of the tool contained a substantial number of individual PWs that overlap by genes, representing sub-segment of the same PWs and creating redundancy. In order to reduce duplication, we clustered nodal PWs based on their gene content. We used complete linkage hierarchical clustering on the Jaccard distance between the complete set of genes in each PW, and identified closely related individual entities.

A measure of the dissimilarity between two PWs (based on their gene sets) scales from 0 to 1 ; ' 0 ' if the sets are exactly the same, and ' 1 ' if they are completely different and have no genes in common. For the purpose of biological interpretations, we considered each cluster of closely related PWs as one unit or mega pathway (dissimilarity cut off of 0.6) and combined all associated differential genes for creating heatmaps and analyzing gene interactions as shown in the Venn diagram (Fig. 1) and a dendrogram (Fig. 2).

To create the heatmaps for selected mega pathways, we plotted $\mathrm{z}$-scored normalized expression levels of differentially expressed genes (FDR $<0.05)$ across all experimental groups (Figs. 3, 4, 5 and 6). The color key ranging from dark blue to dark red shows the z-scored normalized expression level.

\section{Realtime RT- PCR validation of microarray results}

Total RNA was isolated from mouse lung homogenate using TRIzol $^{\circ}$ reagent according to the manufacturer's instructions and purified using the RNeasy ${ }^{\circ}$ Mini Kit according to the manufacturer's protocol (Qiagen, MD, USA). iQ SYBR Green Supermix was used to do the real time RT-PCR using iCycler by Bio-Rad, USA. 18S rRNA (sense, 5'-GTAACCCGTTGAACCCCATT-3', and antisense, $5^{\prime}$ - CCATCCAATCGGTAGTAGCG-3') was used as an external control to normalize expression. Quantitative RT-PCR was performed as previously described [13]. All primers were designed by inspection of the genes of interest and were designed using Beacon Designer 2.1 software. The sequence description of mouse primers used are given in Additional file 1: Table S1. We included negative controls, consisting of reaction mixtures containing all components but for the target RNA, with each of the RT-PCR runs. In order to ensure 


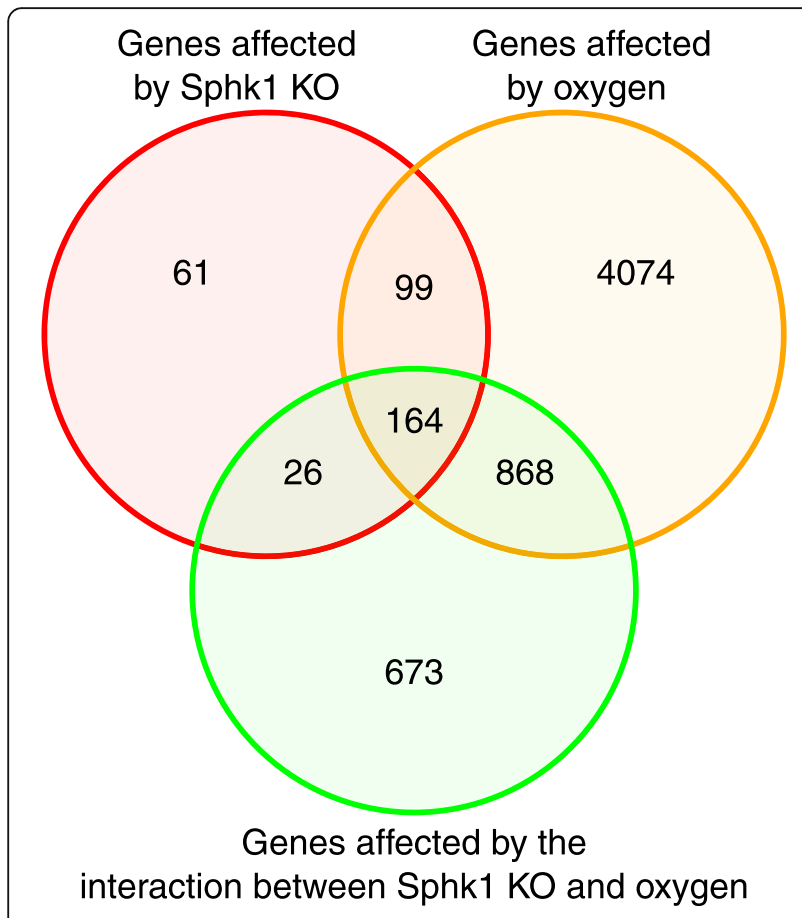

Fig. 1 Venn diagram showing the number of genes differentially regulated in the WT and Sphk ${ }^{-1-}$ neonatal mice exposed to hyperoxia. Two-way ANOVA was performed to analyze the data. There are three variables in the two-way ANOVA performed here such as 1. knock out of Sphk1 gene, 2. hyperoxia, 3. interaction of Sph $k 1^{-/-}$and hyperoxia. Red circle shows all the genes affected by knockout of Sphk1 gene $(61+99+164+26=350)$. Sphk $1^{-/-}$shows 61 genes solely differentially regulated when the corresponding gene was knocked out. Orange circle shows all the genes $(4074+868+99+164=5205)$ affected by hyperoxia. 4074 genes were differentially regulated by hyperoxia compared to the corresponding normoxic control unaffected by other factors. Green circle shows genes affected by the interaction between the two factors i.e., Sphk $1^{-1-}$ and hyperoxia $(673+26+164+868=1731) .673$ genes were solely affected by the interaction between $S p h k 1^{-1-}$ and hyperoxia, independent of the direct impact of either

that amplified products did not represent genomic DNA contamination but the itended mRNA to be amplified, the representative PCR mixtures for each gene were run in the absence of the RT enzyme after first being cycled to $95{ }^{\circ} \mathrm{C}$ for $15 \mathrm{~min}$. No PCR products were observed in the absence of reverse transcription,.

Direct comparison of two groups such as WT HO and Sph $k 1^{-/-}$HO was done using paired $\mathrm{t}$-test. The level of statistical significance was set at $p<0.05$.

All the validation studies were done in the exact same cohort used in microarray studies.

\section{Results}

\section{Outline of the overall transcriptional changes}

Figure 1 is a Venn diagram showing the number of genes differentially regulated in the WT and $S p h k 1^{-/-}$neonatal mice exposed to hyperoxia based on two-way ANOVA analysis. The diagram depicts number of genes affected in three different categories: 1 . Sphk1 gene knockout, 2. Exposure of the neonatal mouse to hyperoxia, 3. Interaction of Sphk1 gene knock out and hyperoxia. The intersecting areas represent genes affected by the corresponding condition. The advantage with two-way ANOVA is that the third variable of interaction between the two factors is purely dependent on interaction, and independent of the direct effect of the two factors.

A total of 4074 genes are differentially regulated by hyperoxia compared to corresponding normoxic control. Differential expression of only 61 genes is noted solely due to the impact of $S p h k 1^{-/-}$whereas 673 genes were affected by the interaction between $\operatorname{Sph} k 1^{-/-}$and hyperoxia.

\section{Pathway enrichment (PW) analyses and elucidation of underlying biological currents}

We identified the top 50 differentially regulated pathways based on the gene expression profiles. Figure 2 depicts a relationship between individual PWs. Additional file 2: Table S2 lists all identified PWs in the order of their position on hierarchical clustering graph, and depicts the clustering of similar pathways. Dissimilarity of 0.6 was used as cut off for the purpose of clustering pathways and reducing the redundancy as described in the Methods. We condensed the data to seven cluster PWs that are differentially regulated among the four groups (WT RA, WT HO, Sph $k 1^{-/-}$RA and Sphk1 $1^{-/-}$HO) studied. Heatmaps show differential expression of selected genes (Figs. 3, 4, 5, 6, 7, 8 and 9).

Most relevant PW clusters are: 1. Cell cycle metaphase check point (cluster 1), 2. DNA damage G2/M check point (cluster 3), 3. DNA-damage-induced apoptosis and survival (cluster 8), 4. Cell adhesion and extracellular matrix remodeling (cluster 10), 5. Pdgf signaling via NF-kB pathway (cluster 11a), 6. Wnt signaling and epithelial mesenchymal transition (cluster 11b), and 7. Sphingosine 1 phosphate (S1P) pathway (cluster 12). The differentially expressed genes in the above PWs are illustrated in the heatmaps (Figs. 3, 4, 5, 6, 7, 8 and 9).

\section{Cell cycle, apoptosis and inflammation}

WT HO shows downregulation of the genes essential to maintain normal cell multiplication in complete contrast with Sphk1 $1^{-/-} \mathrm{HO}$ and control groups. Centromere proteins (Cenp) play a significant role in assembly of kinetochores and maintenance of mitotic checkpoint signaling [19-21]. Cenp $E, F$ and $H$ were significantly downregulated in WT $\mathrm{HO}$ compared to the rest of the groups. Bubr1 and Bub1 genes also play an important role in spindle formation and their expression was downregulated in WT HO whereas their expression was comparable in other groups. 


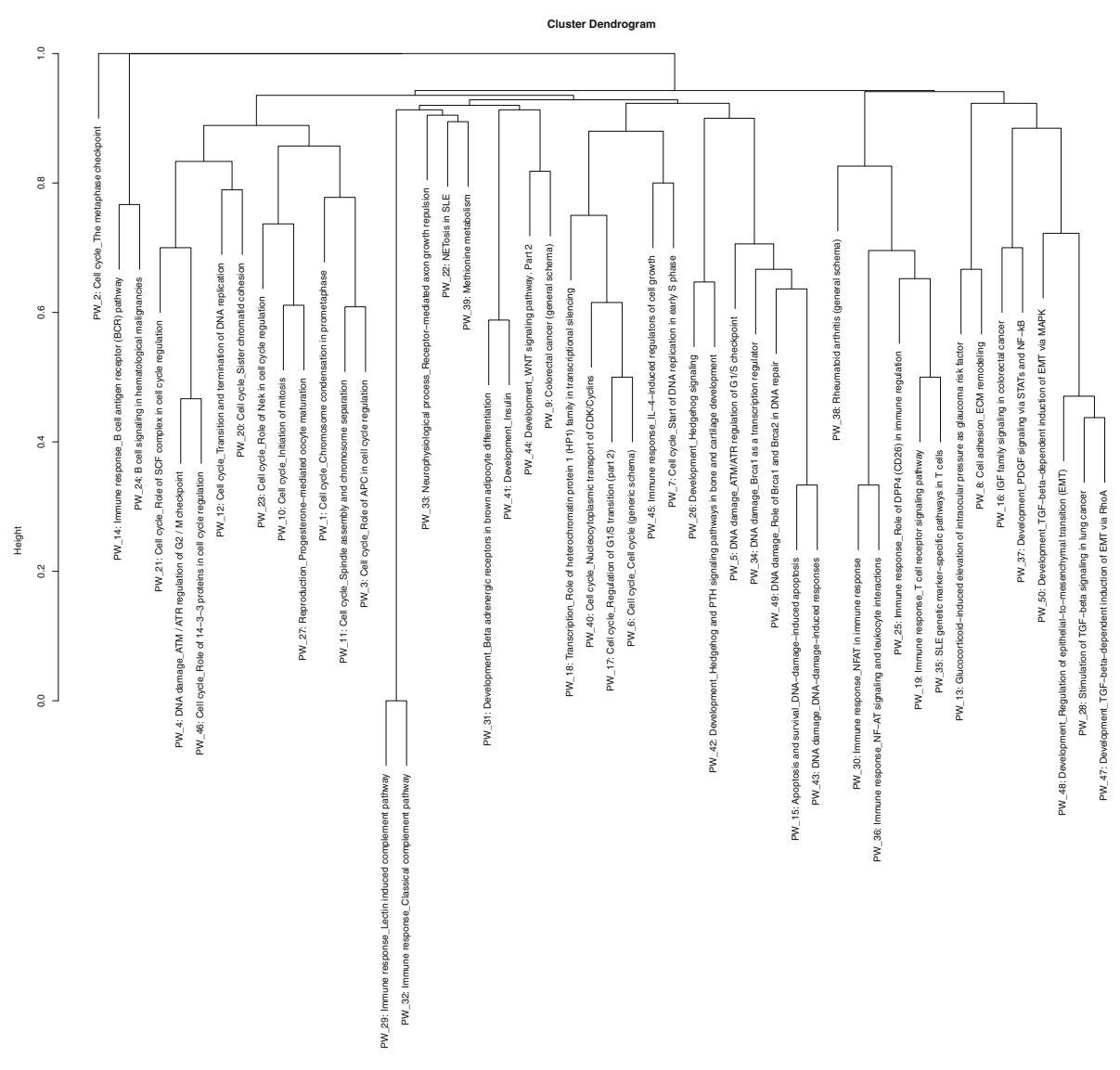

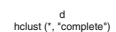

Fig. 2 Nodal biological pathways identified as differentially regulated in the animal model of BPD. Differential gene expression analysis was further subjected to pathway enrichment analysis in order to delineate the underlying major biological signaling pathways that could be attributed to the protective effect seen in Sph $\mathrm{T}^{-1-}$ mice against hyperoxia induced lung injury. The $7 \mathrm{M}$ clusters of pathways were grouped by similar functions, thus highlighting significant differentially expressed genes most prevalent in our model, as shown here. The pathways combined to form clusters are described here. 1. Cell cycle metaphase check point (cluster 1), 2. DNA damage G2/M check point (cluster 3 ), 3. DNA-damage-induced apoptosis and survival (cluster 8), 4. Cell adhesion and extracellular matrix remodeling (cluster 10), 5. Pdgf signaling via NF-KB pathway (cluster 11a), 6. Wnt signaling and epithelial mesenchymal transition (cluster 11b), and 7. Sphingosine 1 phosphate (S1P) pathway (cluster 12). A detailed description of the pathways and how they were combined to form clusters is given in Additional file 2: Table S2

Bax, a proapoptotic gene [22] was upregulated 4 fold in WT HO compared to the rest. In contrast, its expression was downregulated in Sphk1 $1^{-1-}$ HO. Bcl2l, an antiapoptotic gene, was upregulated 2.9 fold in WT HO compared to the WT RA and elevated 2 fold compared to the $S p h k 1^{-/-}$HO.

$p 21$ (Cdkn1a) gene expression was increased 7 fold in WT HO and 6 fold in Sphk1 ${ }^{-1-}$ HO groups compared to normoxia groups. This was accompanied by reduced expression of Cyclin $A, B$ and $E$ genes in the WT HO. Cyclins bind to the dependent kinases, such as the cdk1 protein forming a maturation-promoting factor that facilitates microtubule formation and chromatin remodeling. p21 is a potent cyclin-dependent kinase (Cdk) inhibitor [23, 24]. No difference was noted between the two normoxia groups. In the WT HO, the gene for Wee which inhibits entry of cell into mitosis by inhibiting Cdk1 is upregulated along with Gadd 45 gene, the family of proteins known to promote inflammation. We noted that multiple genes of $W n t$ signaling pathways including Frizzled gene showed a tendency to be downregulated

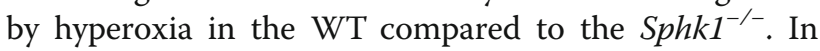
contrast, genes related to promotion of inflammation such as Gadd45 alpha, Cox2, Serpina3, NFkappaB, and $P d g f$ receptor were upregulated in WT HO group compared to $S p h k 1^{-/-} \mathrm{HO}$ and the rest.

\section{Sphingosine 1 phosphate signaling pathway}

As shown in Fig. 9, there was significant increase in expression of Sphk1 in the lungs of WT mice exposed to hyperoxia (3.9 fold). In contrast, S1P lyase gene (Sgpl1) expression was minimally changed under hyperoxia in 


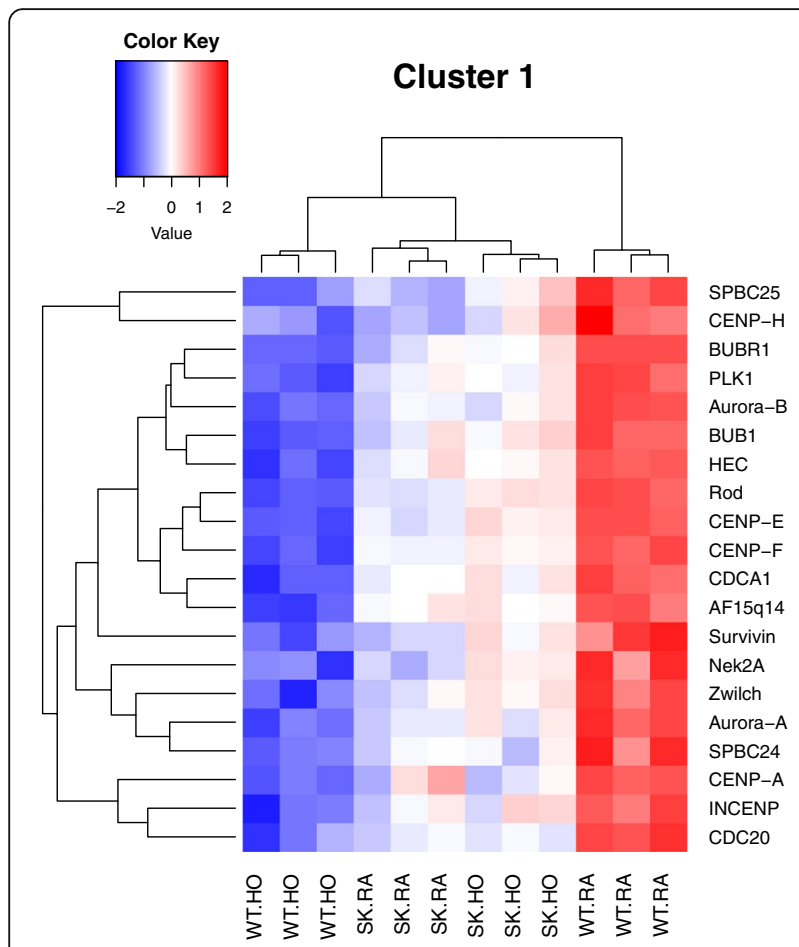

Fig. 3 Heatmap showing differentially regulated genes in the nodal pathway related to cell cycle metaphase check point (cluster 1). Differentially expressed genes were analyzed using the "Pathway Maps" ontology and the top 50 most enriched pathways (PW) were identified. We clustered nodal PWs based on their gene content and reduced duplication. Complete linkage hierarchical clustering on the Jaccard distance between the complete set of genes in each PW was done and closely related individual entities were identified. Each cluster of closely related PWs was considered as one unit or mega pathway (dissimilarity cut off of 0.6). All associated differential genes were combined for creating heatmaps and analyzing gene interactions. Clustering of pathways has been detailed in Additional file 2: Table S2. The color key ranging from dark blue to dark red shows the degree of differential regulation from -2 of down regulation or more to +2 of upregulation or more. The color key ranging from dark blue to dark red shows the z-scored normalized expression level. This heatmap depicts the biological nodal pathway showing differential regulation of genes among the 4 different groups such as WT neonatal mice exposed to room air (WT RA), hyperoxia (WT HO), Sphk1 $1^{-1-}$ mice exposed to room air (SK RA), or Sphk $1^{-1-}$ mice exposed to hyperoxia (SK HO). Selected genes depicted in the heat map is described here. Among the genes prominently downregulated by hyperoxia in the $\mathrm{WT}$ include 1) centromere associated proteins, Cenp A, E, F and H, 2) Kinetochore proteins Bubr, Aurora A and B, Bub1 and Zwilch and 3) protein kinases such as Nek2a

the WT. No significant difference was noted in the gene expression of the S1P transporter Spns2 between various groups. S1P receptor 1 gene (S1pr1) was noted to be upregulated in WT HO (2.26 fold) compared to Sphk1 $1^{-/-}$ HO. Interestingly, S1pr2 expression was relatively lower in $\operatorname{Sph} k 1^{-1-} \mathrm{RA}$ mice that only increased by 1.3 fold upon exposure to hyperoxia. S1pr3 gene expression showed a tendency to go down in WT HO compared to

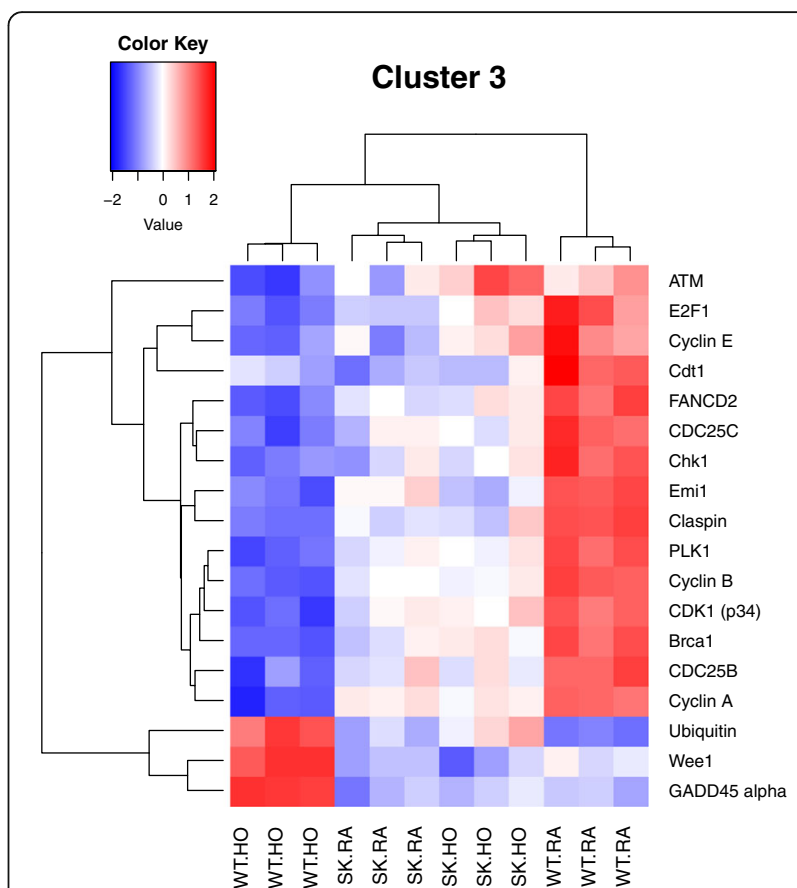

Fig. 4 Heatmap showing genes differentially regulated in the nodal pathway related to mostly DNA damage G2/M check point (cluster 3). The cluster combines data from 11 related pathways as shown in Additional file 2: Table S2. Selected genes depicted in the heatmap are described here. Among the genes prominently downregulated by hyperoxia in the WT are 1) Cyclins A, B and D, Cdk1, 2) ATM serine/ threonine kinase, Chk1. ATM is activated by DNA double-strand breaks. In contrast, gene for Wee was upregulated in WT HO along with Gadd45 alpha

WT RA. Among the bioactive lipids lysophosphatidic acid (LPA) is an important molecule and is part of the lysophospholipid (LP) family. Lysophosphatidylcholine is converted into LPA by the secreted enzyme, autotaxin. We noted a reduction in autotaxin by 1.9 fold in the WT HO and larger 3.2 fold reduction of this gene expression in Sphk1 $1^{-1-}$ HO. LPA receptors (Lpar) were also differentially expressed in our study. Lpar2 and 3 were significantly upregulated in WT HO compared to the rest whereas Lpar4 was downregulated.

Following identification of the PWs, we validated differential expression of specific genes by their biological impact as revealed in our neonatal BPD mouse model, and also by real time RT-PCR.

Biological impact of Sphk1 deletion in the animal model correlates with the differential expression of genes

Our animal data correlated strongly with the genes previously identified as differentially expressed in early BPD, and strongly supported the current findings (Table.1). For instance, increased expression of SphK1 mRNA (Fig. 9, Table.1) corresponded to our previous observation that SphK1 protein expression is elevated in 


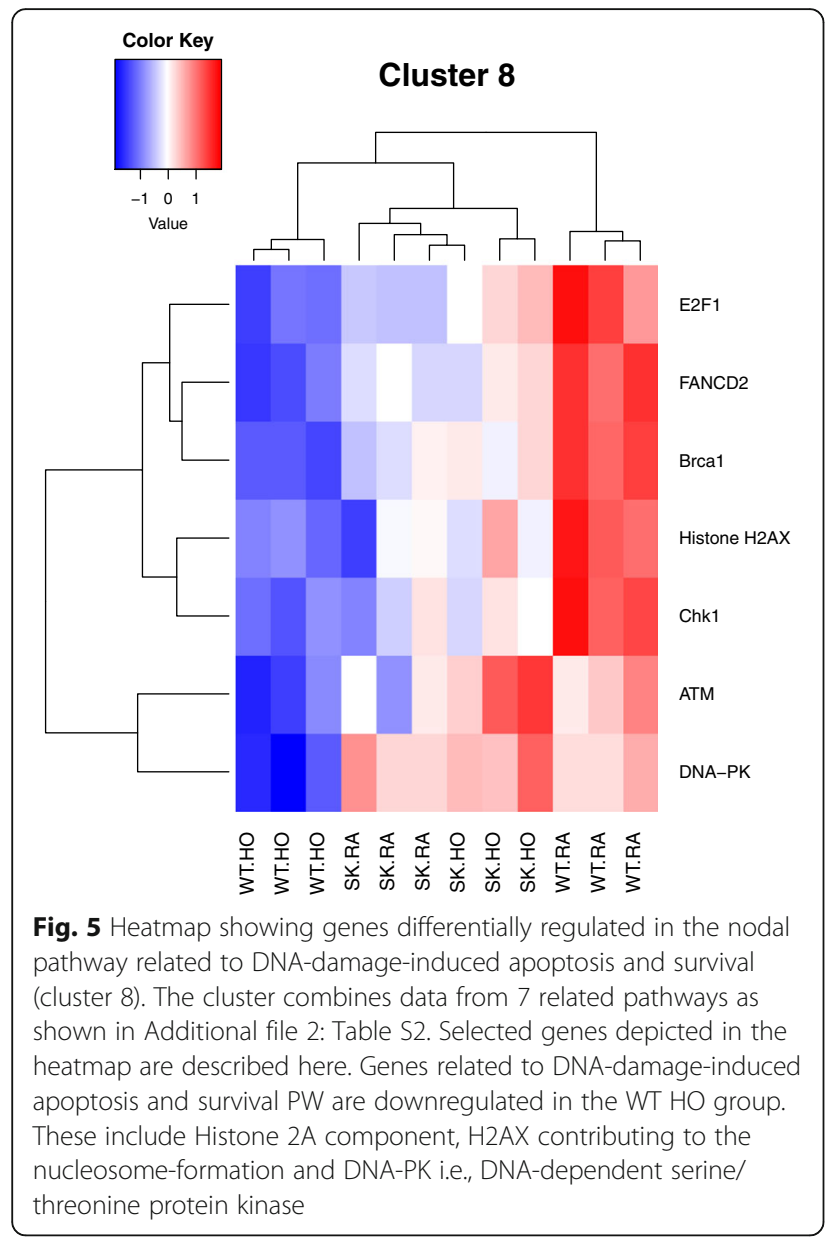

neonatal mice exposed to hyperoxia [13, 25]. We have also shown that $S p h k 1^{-1-}$ mice exhibited decreased lung S1P levels compared to WT both under normoxia and hyperoxia [25]. IL-6 cytokine level was found to be significantly decreased in the bronchoalveolar lavage (BAL) fluid of $S p h k 1^{-/-}$mice compared to the WT exposed simultaneously to hyperoxia [13]. Here, we show that genes of the IL-6 family including its receptors were downregulated in the Sphk1 $1^{-1-} \mathrm{HO}$ compared to the WT HO. Increased infiltration of neutrophils in the BAL fluid and lung tissue in the WT HO group was noted compared to $S p h k 1^{-/-} \mathrm{HO}$ and the RA controls. This correlated well with the increased expression of genes related to neutrophil activation such as L, E, P-Selectin and P-Selectin glycoprotein ligand-1 in the WT HO group compared to $\mathrm{Sphk}^{-/-} \mathrm{HO}$ and the RA controls. Another interesting finding was increased expression of genes coding for proteins involved in DNA damage and apoptosis such as Gadd and Diablo in the WT HO

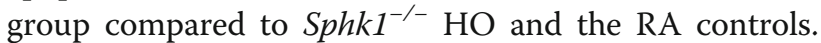
This finding correlated well with increased apoptosis observed in the lung tissue of the WT HO group compared to $S p h k 1^{-1-} \mathrm{HO}$ and the RA controls.

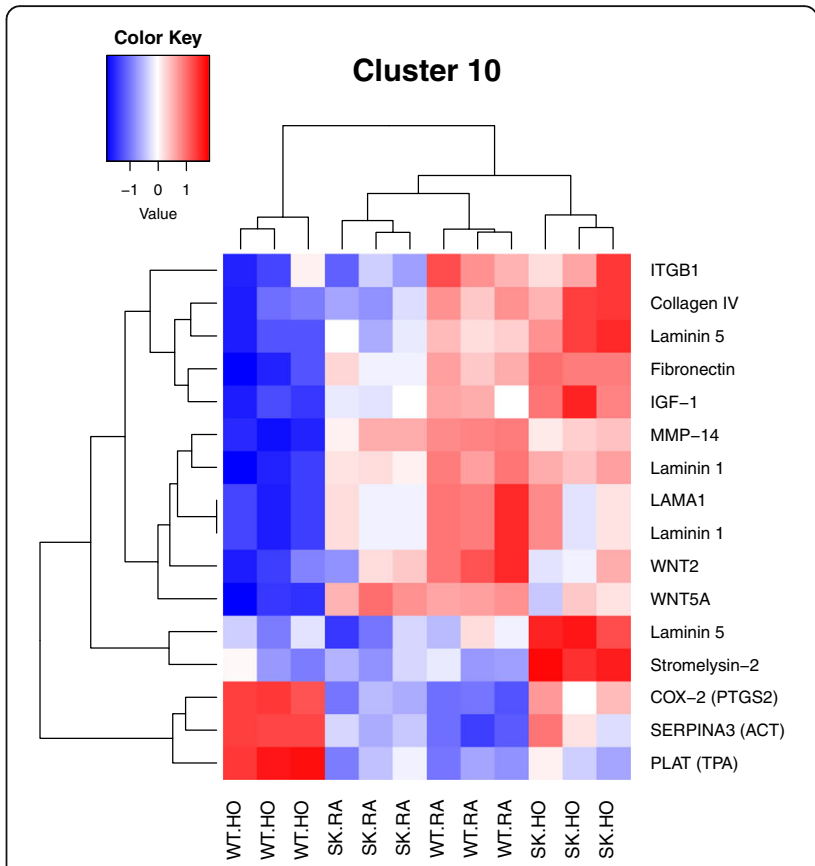

Fig. 6 Heatmap showing genes differentially regulated in the nodal pathway related to cluster 10. The cluster combines gene expression analysis data from glucocorticoid-induced elevation of intraocular pressure as glaucoma risk factor and cell adhesion and extracellular matrix remodeling. Among the genes downregulated in WT HO in contrast to Sphk $1^{-/-} \mathrm{HO}$ are those coding for basal lamina such as Laminin 1, 5 and Collagen IV, matrix metalloproteinases such as MMP-14, MMP-3 (Stromelysin-1) and integrin beta sub unit (ITGB). Laminin-5 and Stromelysin-1 are upregulated significantly in Sphk1 ${ }^{-1-} \mathrm{HO}$. Genes significantly upregulated in WT HO are those coding for Cox 2, Serpina 3 and Plat. Cyclooxygenase (COX) catalyzes formation of prostaglandins such as prostacyclin. Serpina 3 gene codes for alpha 1-antichymotrypsin which inhibits the activity of proteases, and thereby protects tissues from proteolytic damage. Sphk1 $1^{-/-} \mathrm{HO}$ also revealed upregulation of Cox 2 and Serpina 3 gene expression in response to hyperoxia

\section{Realtime RT- PCR validation of microarray results}

Table. 2 and Fig. 10 a \& b show realtime RT-PCR performed on select 24 genes based on the observations made from microarray gene expression analysis. Of the 24 genes selected, RT-PCR confirmed differential expression of 21 genes, suggesting an $83 \%$ validation. The rationale behind choice of genes for validation is as follows. Serpina3n; the most highly upregulated gene in the WT HO group compared to WT RA was an obvious choice for RT-PCR. The most highly upregulated gene in the WT HO group compared to $S p h k 1^{-/-}$HO was Chi3l3. The most highly downregulated genes common to both HO groups was Stfa1 [26]. Aplnr was noted to be significantly downregulated in both HO groups. Saa3 was the most highly upregulated gene in $S p h k 1^{-1-} \mathrm{HO}$

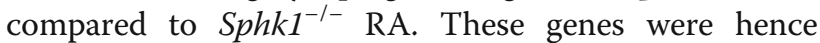
chosen as candidates for validation. In addition, $I L-6$, IL6st, IL6ra, Gadd45a, Gadd45g, Cdkn1a, Bax, Serpine1, Cdkn1b, Bmp7, Wnt5a, Lox, Cdh2, Sphk1, Sgpl1, S1pr1, 


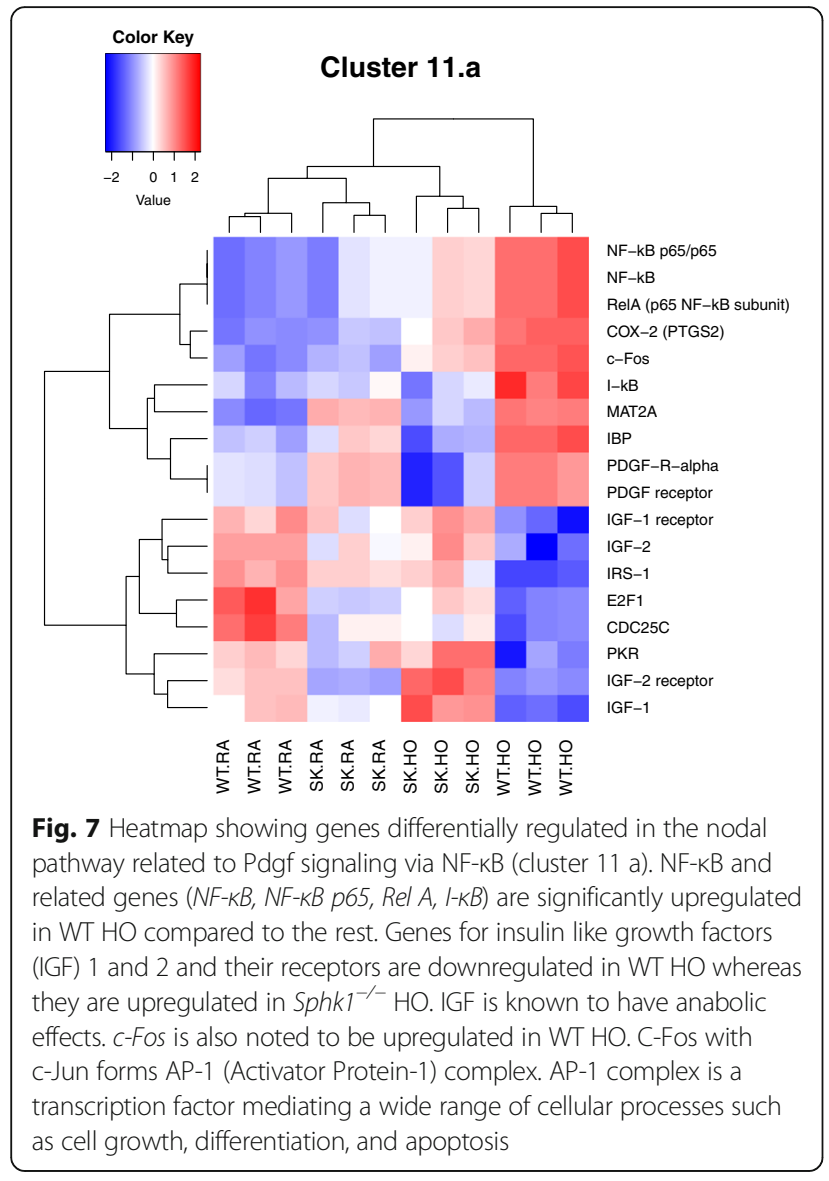

S1pr2, S1pr3, and Lpar3, were chosen from various differentially regulated nodal pathways as they were related to inflammation, cell proliferation and apoptosis, lung development and S1P signaling. More importantly, these genes were also related to biologically relevant findings in our animal model. S1P receptor 2 did not show significant change in the microarray data at gene level, but mRNA showed significant increase in WT HO which was less pronounced in Sphk1 $1^{-1-}$ HO. Sgpl1 did not show any change in the microarray but WT HO showed significant decrease in the RT-PCR validation. S1P receptor 3 gene in microarray showed a tendency to go down in WT HO which was exaggerated further in the RT-PCR. Though we noted an increased expression of Nox 2 and 4 at both mRNA and protein levels, we did not see a similar increase in the microarray. A brief list of most differentially expressed genes by direct comparison between the four groups of WT RA, WT HO, Sphk1 -/- RA and $\operatorname{Sphk1}^{-/-} \mathrm{HO}$ is given in Additional file 3: Table S3, Additional file 4: Table S4, Additional file 5: Table S5, and Additional file 6: Table S6.

\section{Discussion}

Neonatal mice exposed to hyperoxia reveal all the major pathological features of human BPD, and therefore serve

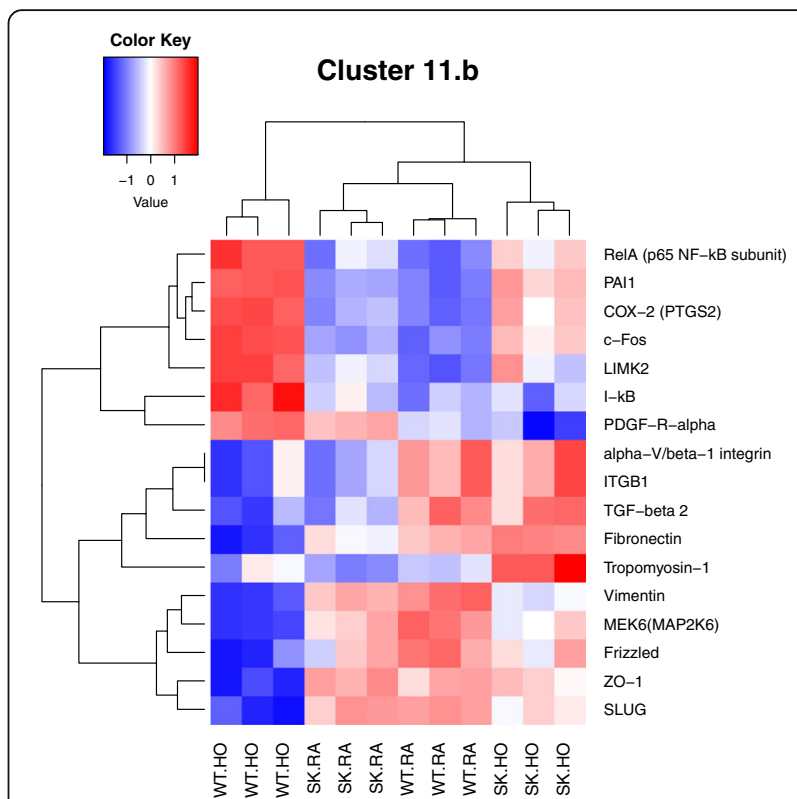

Fig. 8 Heatmap showing genes differentially regulated in the nodal pathway related to Wnt signaling and epithelial mesenchymal transition (EMT) (cluster 11 b). The following genes related to EMT were downregulated in WT HO: alpha - V/beta - 1 integrin,

fibronectin, vimentin, slug, Zo-1. Frizzled and Wnt signaling were also noted to be downregulated in WT HO. Gene for LIM Domain Kinase 2 (Limk 2) was upregulated in WT HO along with other genes described earlier. Limk2 is known to inactivate cofilin and induce formation of stress fibers and focal complexes

as an excellent model to investigate the underlying pathologies and to identify potential therapeutic targets $[27,28]$. S1P has been shown to play dual roles, both protective as well as pathological, depending upon the clinical, i.e., pathological situations [13, 29, 30]. It is currently known that in asthma, S1P induces degranulation of mast cells and promotes adverse remodeling response of airway smooth muscle cells [31, 32]. Inhibition of S1P receptors using Fingolimod serves as the only effective therapy against multiple sclerosis [33]. However, it has also has been shown that S1P promotes endothelial integrity in sepsis model of endothelial injury [30]. In this background, we showed in our previous study using Sphk1 $1^{-/-}$neonatal mice that S1P/SphK1 promotes hyperoxic lung injury by promoting formation of ROS [13]. ROS production was mediated through $\mathrm{S}_{1} \mathrm{P}_{1}$ and $\mathrm{S} \mathrm{P}_{2}$ receptor signaling [25]. The opposing effects of SphK1 and SphK2 also have been described earlier [34]. The two enzymes are located in different compartments of the cell, and the production of localized S1P has distinct functions. SphK1 has been shown to be predominantly cytosolic whereas SphK2 is considered a nuclear protein [35]. Deletion of SphK1 results in about 50\% reduction in serum levels of S1P whereas deletion of SphK2 results in only about $25 \%$ reduction of S1P 


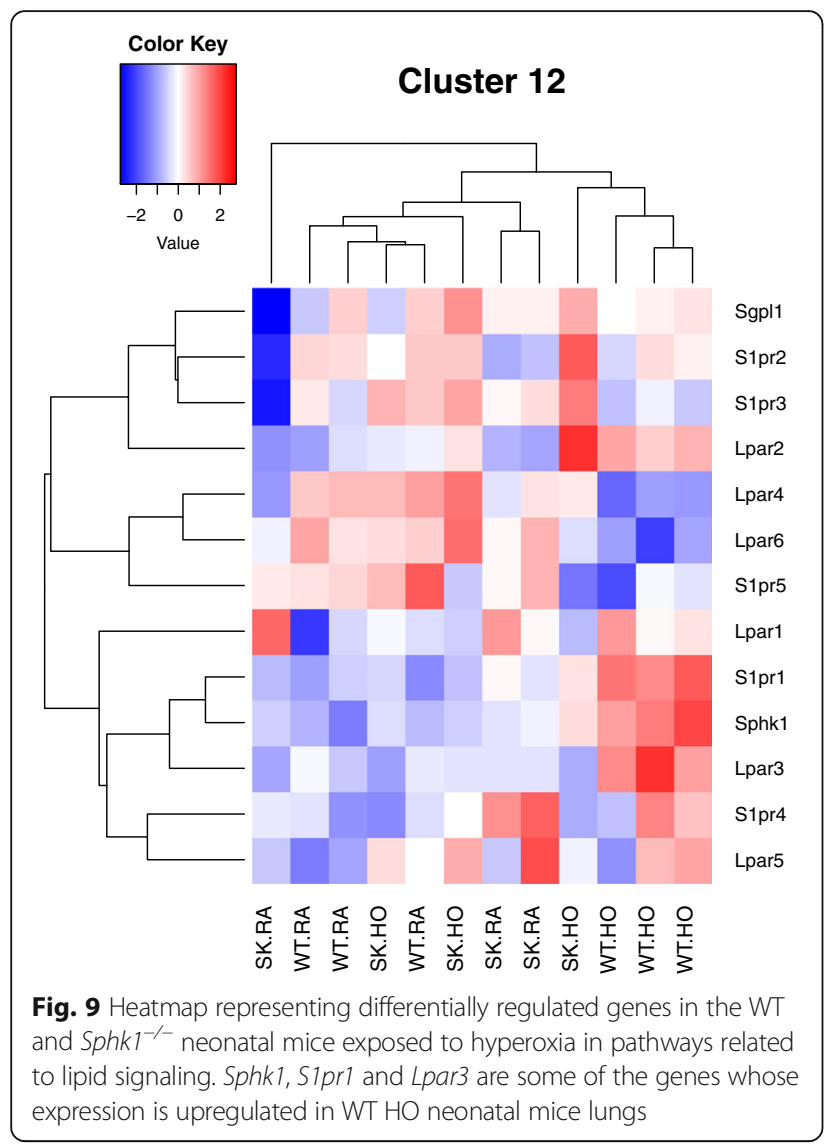

$[25,36]$. The reason for this is not known though the production of S1P can be compensated by one enzyme in the absence of the other. Under normoxia, there is no morphological difference or difference in life span between WT and Sphk1 $1^{-/-}$mice. S1P is essential for normal lung development as it plays a significant role in angiogenesis essential for alveolar formation [37]. In addition, even complete knock out of SphK 1 enzyme resulted in only 50\% reduction of S1P levels as SphK 2 compansates for the loss of SphK1. The difference is exaggerated only under pathological conditions such hyperoxia when an increase in SphK1 enzyme expression is prevented in $\operatorname{Sph} k 1^{-/-}$mice. This could be the reason for similarity of gene expression between WT and Sphk1 $1^{-/}$at baseline normoxia. Under hyperoxia, an elevated expression of SphK 1 leads to increased production of S1P followed by reduced ROS production in the lungs. Deletion of SphK1 also attenuated inflammation and apoptosis under hyperoxia. In order to further understand the key players in hyperoxic lung injury in neonates, we applied microarray based differential gene expression analyses. In general, we observed a strong agreement between our previous in vivo findings in the neonatal mouse BPD model and specific differential gene expression profiles revealed in the present study and the data is summarized in Table 1.

Several novel findings that logically fit into the pathology of BPD emerged from the current study. Centromere proteins Cenp E, F and $\mathrm{H}$ were significantly downregulated in WT HO compared to the rest of the groups. Cenp E appears during prometaphase, Cenp $\mathrm{F}$ in the late anaphase and telophase whereas Cenp $\mathrm{H}$ in both interphase and metaphase [38, 39]. Downregulation of these proteins that play a crucial role in the assembly of kinetochores and spindle elongation will invariably dampen cell proliferation leading to the arrest of organ growth [40, 41]. Another example is the case with Bub1 and Aurora B kinase genes which were downregulated in WT HO but not so in Sphk1 - - HO. Bub1 and Aurora B kinase work in tandem, promoting formation of stable bipolar kinetochoremicrotubule attachments [42]. Both Bub1 and Aurora B kinase are recruited to kinetochores independent of each

Table 1 Validation of differential gene expression noted in the microarray by comparing with the biological impact noted in the same animal model

Differential expression of genes in animal model
Biological impact noted in our animal model (Ref 13) Sphk $1^{-1-} \mathrm{HO}$ and the RA controls.

Increased expression of genesrelated to IL-6 such as 116 , II6 receptor alpha and II6 signal transducer in the WT HO group compared to Sphk $1^{-/-} \mathrm{HO}$ and the RA controls.

Increased expression of genes related to neutrophil activation such as $L, E$, P-Selectin and P-Selectin glycoprotein ligand-1 in the WT HO group compared to Sphk $1^{-1-} \mathrm{HO}$ and the RA controls.

Increased expression of genes coding for proteins aggravating DNA damage and apoptosis such as Gadd and Diablo in the WT HO group compared to Sphk1 $1^{-1-} \mathrm{HO}$ and the RA controls.

Increased expression of genes regulating inflammation in the WT HO compared to Sphk $1^{-1-} \mathrm{HO}$ and the RA controls.
Increased expression of mRNA and protein of SphK1 in the WT HO group compared to Sphk $1^{-/-} \mathrm{HO}$ and the RA controls. Severe lung injury leading to BPD lung morphology in WT HO. Lung injury protection in Sphk $1^{-/-} \mathrm{HO}$.

Increased levels of II-6 measured in the BAL fluid of WT HO group compared to Sphk $1^{-1-} \mathrm{HO}$ and the RA controls.

Increased infiltration of neutrophils in the BAL fluid and lung tissue in the WT HO group compared to Sphk $1^{-1-} \mathrm{HO}$ and the RA controls.

Increased apoptosis in the lung tissue of the WT HO group compared to Sphk ${ }^{-/-} \mathrm{HO}$ and the RA controls.

Increased cell infiltration and concentration of protein in the BAL fluid of the WT HO group compared to Sphk $1^{-1-} \mathrm{HO}$ and the RA controls 
Table 2 Microarray data validation by RT-PCR. This table shows a comparison between the differential expression detected by microarray with the corresponding transcript values using RT-PCR. Using RT-PCR, we validated 20/24 genes suggesting 83\% concordance between the two methods

\begin{tabular}{|c|c|c|c|c|c|}
\hline & & $\begin{array}{l}\text { WT RA } \\
\text { Fold change }\end{array}$ & $\begin{array}{l}\text { WT HO } \\
\text { Fold change }\end{array}$ & $\begin{array}{l}\text { Sphk } 1^{-1-} \text { RA } \\
\text { Fold change }\end{array}$ & $\begin{array}{l}\text { Sphk1 }{ }^{-1} \mathrm{HC} \\
\text { Fold change }\end{array}$ \\
\hline \multirow[t]{2}{*}{ Gadd45a } & Microarray Fold Change & 1 & 3.63168 & 0.921811 & 1.002221 \\
\hline & RTPCR & 1 & 2.579674 & 0.908044 & 0.967095 \\
\hline \multirow[t]{2}{*}{ Gadd45g } & Microarray Fold Change & 1 & 8.38319 & 1.43496 & 2.705904 \\
\hline & RTPCR & 1 & 6.245498 & 1.100627 & 2.153558 \\
\hline \multirow[t]{2}{*}{ Cdknia } & Microarray Fold Change & 1 & 7.99461 & 1.2607 & 7.897151 \\
\hline & RTPCR & 1 & 13.72415 & 1.537082 & 12.61852 \\
\hline \multirow[t]{2}{*}{ Bax } & Microarray Fold Change & 1 & 3.87613 & 1.16573 & 2.869782 \\
\hline & RTPCR & 1 & 3.43179 & 1.032757 & 2.079701 \\
\hline \multirow[t]{2}{*}{ Serpine1 } & Microarray Fold Change & 1 & 15.4903 & 1.32755 & 5.559448 \\
\hline & RTPCR & 1 & 8.024327 & 0.94901 & 3.421921 \\
\hline \multirow[t]{2}{*}{$C d k n i b$} & Microarray Fold Change & 1 & 0.708453 & 1.16238 & 0.75834 \\
\hline & RTPCR & 1 & 0.740789 & 1.324503 & 1.318684 \\
\hline \multirow[t]{2}{*}{ Serpina3n } & Microarray Fold Change & 1 & 75.388 & 3.72853 & 14.3611 \\
\hline & RTPCR & 1 & 18.49097 & 1.648514 & 4.635865 \\
\hline \multirow[t]{2}{*}{ Saa3 } & Microarray Fold Change & 1 & 5.19527 & 0.517552 & 15.89733 \\
\hline & RTPCR & 1 & 4.095082 & 0.74759 & 11.46964 \\
\hline \multirow[t]{2}{*}{ Bmp7 } & Microarray Fold Change & 1 & 0.907484 & 0.817163 & 1.759001 \\
\hline & RTPCR & 1 & 0.821678 & 0.857167 & 3.075663 \\
\hline \multirow[t]{2}{*}{ Wnt5a } & Microarray Fold Change & 1 & 0.2359 & 1.07608 & 0.638945 \\
\hline & RTPCR & 1 & 0.152372 & 0.926221 & 0.623315 \\
\hline \multirow[t]{2}{*}{ Cdh2 } & Microarray Fold Change & 1 & 0.642012 & 0.879343 & 0.764438 \\
\hline & RTPCR & 1 & 0.199199 & 0.924477 & 0.879041 \\
\hline \multirow[t]{2}{*}{ Aplnr } & Microarray Fold Change & 1 & 0.049004 & 1.06134 & 0.147246 \\
\hline & RTPCR & 1 & 0.092198 & 1.04678 & 0.375555 \\
\hline \multirow[t]{2}{*}{ S1pr1 } & Microarray Fold Change & 1 & 2.26942 & 1.17521 & 1.116978 \\
\hline & RTPCR & 1 & 4.894727 & 0.889052 & 0.87604 \\
\hline \multirow[t]{2}{*}{ S1pr2 } & Microarray Fold Change & 1 & 0.921563 & 0.750461 & 0.997753 \\
\hline & RTPCR & 1 & 3.656166 & 0.81154 & 1.212284 \\
\hline \multirow[t]{2}{*}{ S1pr3 } & Microarray Fold Change & 1 & 0.933923 & 0.936387 & 1.03291 \\
\hline & RTPCR & 1 & 0.415816 & 0.944109 & 0.978297 \\
\hline \multirow[t]{2}{*}{ Lox } & Microarray Fold Change & 1 & 1.30887 & 1.04026 & 1.181007 \\
\hline & RTPCR & 1 & 2.450447 & 0.932973 & 1.175259 \\
\hline \multirow[t]{2}{*}{$1 / 6 s t$} & Microarray Fold Change & 1 & 1.79941 & 1.29187 & 1.072552 \\
\hline & RTPCR & 1 & 2.79062 & 0.905679 & 0.820019 \\
\hline \multirow[t]{2}{*}{116} & Microarray Fold Change & 1 & 5.55994 & 1.29187 & 3.028182 \\
\hline & RTPCR & 1 & 6.072546 & 0.791731 & 1.45494 \\
\hline \multirow[t]{2}{*}{$116 r a$} & Microarray Fold Change & 1 & 1.64621 & 1.40755 & 1.136742 \\
\hline & RTPCR & 1 & 2.101202 & 1.082853 & 0.876843 \\
\hline \multirow[t]{2}{*}{ Sgp/1 } & Microarray Fold Change & 1 & 0.997442 & 0.890375 & 0.938402 \\
\hline & RTPCR & 1 & 0.424413 & 0.963454 & 0.875726 \\
\hline \multirow[t]{2}{*}{ Sphk1 } & Microarray Fold Change & 1 & 3.70231 & 1.51325 & 1.556574 \\
\hline & RTPCR & 1 & 4.364135 & 1.047004 & 1.149245 \\
\hline
\end{tabular}


Table 2 Microarray data validation by RT-PCR. This table shows a comparison between the differential expression detected by microarray with the corresponding transcript values using RT-PCR. Using RT-PCR, we validated 20/24 genes suggesting 83\% concordance between the two methods (Continued)

\begin{tabular}{llllll}
\hline Lpar3 & Microarray Fold Change & 1 & $\mathbf{1 . 7 8}$ & 0.95 & 0.83 \\
& RTPCR & 1 & $\mathbf{2 . 1 5 3 5 5 8}$ & 1.008994 & 0.773786 \\
Chi3/3 & Microarray Fold Change & 1 & $\mathbf{2 6 . 0 6 1 5}$ & 4.07383 & 1.2288 \\
& RTPCR & 1 & $\mathbf{2 2 . 8 0 7}$ & 3.806 & 1.5576 \\
Stfa1 & Microarray Fold Change & 1 & $\mathbf{0 . 0 6 6 3 9 6 4}$ & 0.505696 & $\mathbf{1 . 8 9 9 2 4}$ \\
& RTPCR & 1 & $\mathbf{0 . 0 5 3 7}$ & .62 & $\mathbf{2 . 0 8 6}$ \\
\hline
\end{tabular}

Bold Differentially regulated gene expression

other but have an additive effect when depleted simultaneously. Bubr1 stabilizes kinetochore-microtubule attachment and helps chromosome alignment by associating with unattached/incorrectly attached kinetochores [42]. Bubr1 forms part of the mitotic checkpoint complex (MCC) that also contains Bub3. Bub 1 depletion leads to the accumulation of misaligned chromatids [42]. It is very likely that the above kinetochore related genes will influence cell division and proliferation, and thus indirectly may contribute to elevated apoptosis seen in hyperoxia induced neonatal lung damage, and needs further investigation.

Interestingly, increased $p 21$ (Cdkn1a) gene expression was observed in both WT HO and Sphk1 $1^{-1-}$ HO groups compared to normoxia groups. This is consistent with previous studies in mammalian and human cells exposed to hyperoxia that show a block in the G1 to S phase progression mediated by an increase in Cdk inhibitor p21WAF1/CIP1 within the first $12 \mathrm{~h}[23,24,43]$. Cell cycle arrest is essential for the repair of hyperoxia induced tissue damage, and to avoid the replication and propagation of cells that harbor potentially hazardous mutations [44, 45]. The role of Cdk inhibitor p21 in causing cell cycle arrest is controversial. On one hand, it has been shown to act as an inhibitor of apoptosis while on the other hand, it has also been shown to induce cell proliferation [46]. The differences in response to hyperoxia seen in WT HO and Sphk1 ${ }^{-1-} \mathrm{HO}$ are hence unlikely to be mediated through p21.

Despite an increased expression of p21, there was preserved alveolarization in the $\operatorname{Sph} k 1^{-/-} \mathrm{HO}$ group compared to WT HO. This is supported by the current observation that Wnt signaling pathways were better preserved in the $S p h k 1^{-/-}$HO group compared to WT HO. Wnt/ $\beta$-catenin1 pathway is known to play a critical role in normal lung development [47]. In contrast, expression of promoters of inflammation such as Gadd45 alpha, Cox2, Serpina3 and NFkappaB were upregulated in WT HO group compared to Sphk1 $1^{-/-}$HO. The present findings are also in agreement with our observation made in the lungs of adult mice exposed to hyperoxia [25]. Gadd45 and Gadd153 mRNAs were detected respectively after 48 and $72 \mathrm{~h}$ of exposure of adult mice to hyperoxia [48]. In situ hybridization and immunohistochemistry studies showed that in hyperoxia Gadd45 and Gadd153 expression were increased in the bronchiolar epithelium and type II alveolar cells, respectively.

Cell cycle arrest is known to trigger apoptosis. In our previous study, we noted a clear increase in apoptosis in the lungs of WT neonatal mice exposed to hyperoxia [25]. Our current findings are in accordance with the above finding. $B c l-X L(B c l 2 l)$, an antiapoptotic gene, was upregulated 2 fold in WT HO compared to Sphk1 ${ }^{-1-} \mathrm{HO}$ but more interestingly, $B a x$ which is a proapoptotic gene was upregulated 4 fold in WT HO compared to the rest. The gene was downregulated in $\operatorname{Sph} k 1^{-/-}$compared to the WT HO. Studies have shown that increases of the antiapoptotic gene $B c l-X L$ were counterbalanced by similar increases of the proapoptotic gene $\operatorname{Bax}$ [49]. In our study, we see an increase in proapoptotic gene in both WT and Sph $\mathrm{K1}^{-/-}$groups exposed to HO but rise in proapoptotic as well as antiapoptotic genes was less pronounced in Sphk1 $1^{-/-}$compared to WT exposed to HO.

Delving further into lipid mediated signaling other than S1P, we noted a significant increase in gene expression of LPA receptor 3 in the WT HO (1.78 fold increase with FDR of 0.014869 ) which is in agreement with hyperoxia studies carried out in rat BPD models [50]. Related studies in humans and rats revealed increased protein expression of autotaxin, Lpar1 and Lpar3 that co-localized to airway epithelial cells following exposure to hyperoxia [51]. These proteins were significantly distributed in vascular endothelial and mesenchymal cells during the developmental phase of the lung in the first postnatal week. It will be interesting to see the distribution of LPA receptors in lung epithelium of neonatal mice exposed to normoxia and hyperoxia.

Human airway epithelial cell lines, including BEAS-2B, NCI-H292, and A549, increase their intracellular glutathione levels within hours in response to hyperoxia in vitro $[52,53]$. The underlying mechanism could be due to elevated levels of glutamylcysteine ligase that is essential for novo synthesis of glutathione; however, we did 


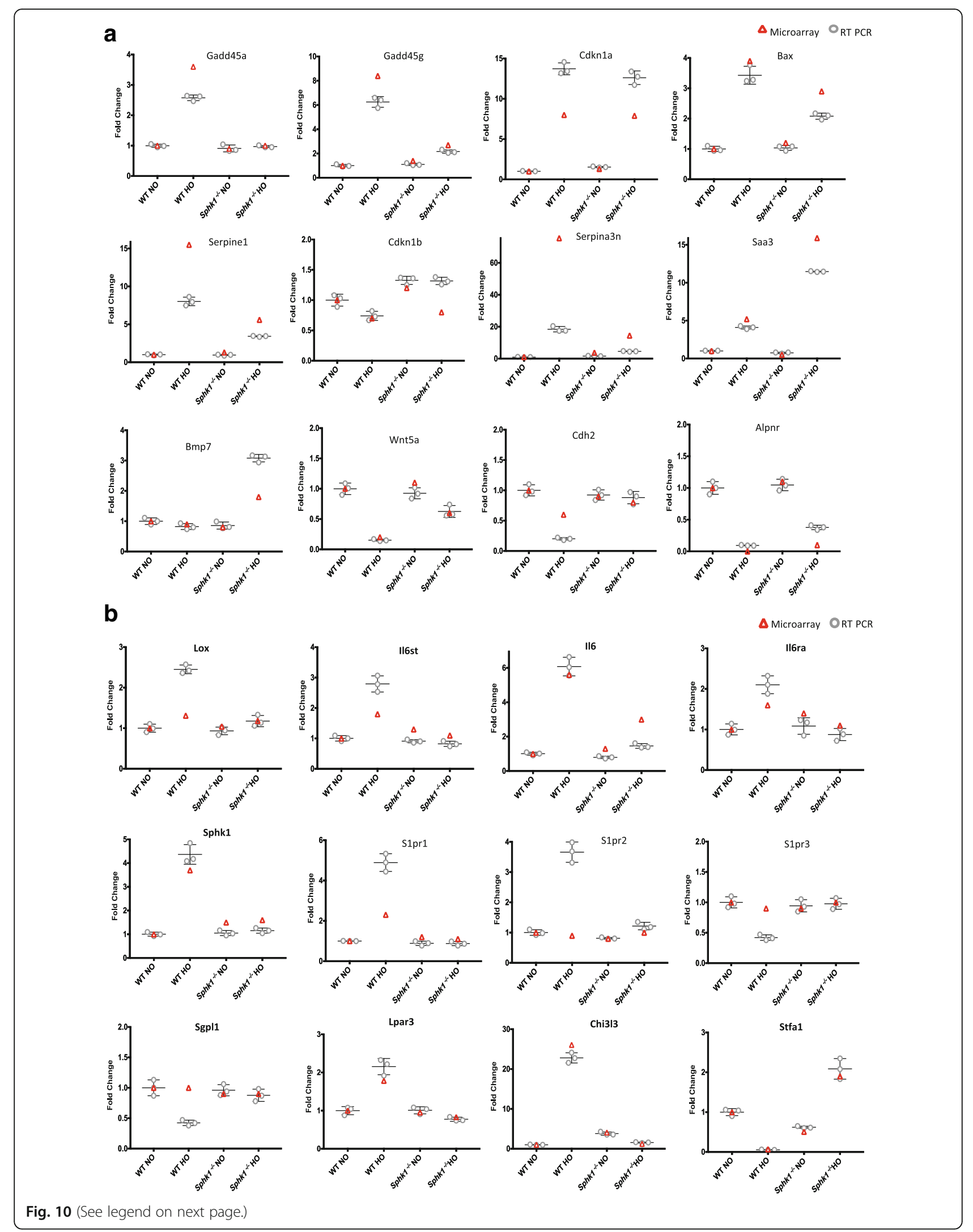


(See figure on previous page.)

Fig. 10 a \& $\mathbf{b}$. Validation of microarray by RT-PCR. The figures represent microarray results in red open triangles and RT-PCR in gray open circles. The four different groups were: WT neonatal mice exposed to normoxia (WT RA), hyperoxia (WT HO), Sphk1 ${ }^{-1-}$ mice exposed to normoxia (SK RA), or hyperoxia (SK HO). Each graph in the figure represents the corresponding gene studied. The gene names are shown at the top of each individual graph. The validation is evidenced by agreement in vectoral change between microarray and RT-PCR. The fold change may differ between the two methods

not see any change in expression of glutamylcysteine ligase following exposure to hyperoxia.

Though we noticed 83\% correlation between microarray and RT-PCR, there was lack of correlation noted in $17 \%$. The disparity in expression between gene and mRNA could be due to the following factors. Microarray data reflects the total expression of the whole genome studied whereas mRNA expression by RT-PCR reflects the changes in a particular part of the genome studied by the primers selected. In addition, the mRNA transcribed would undergo post-transcriptional modification to form the final mRNA which undergoes translation.

We also compared the current differential gene expression data in response to hyperoxia in the neonatal mouse BPD model to the human data on BPD (Table 3). The BPD in humans is classified into 'Early' and 'Late' gestation by the authors [54]. 'Early' gestation was defined as estimated gestational age (EGA) of $<27$ wk. at birth and $<35$ wk. EGA at death. 'Late' gestation was defined as estimated gestational age of $>27$ wk. at birth and $>35$ wk. EGA at death. A total of 159 genes were significantly affected in the BPD lung tissue as compared to the controls in humans [54]. 36 of these genes that were significantly regulated were common between the present study and the human data. Out of the 36 genes, 11 correlated with the differential gene regulation in our animal model. Among those genes, we noted that the expression of human genes IL1RL1, SFN, SH3RF2 and SELE was significantly elevated in human BPD as well as in murine WT HO. CD177, ALDH1A3, CXCL5, and $M A R C O$ gene expression was significantly elevated in

Table 3 Comparison of the current differential gene expression analysis to published human BPD microarray data. Human lung microarray had four groups such as early gestation control, late gestation control, early BPD and late BPD. Genes found to be differentially regulated in response to hyperoxia that are common to human and mouse neonatal lungs are presented here

\begin{tabular}{|c|c|c|c|c|c|c|c|}
\hline Gene Symbol (Gene name) & $\begin{array}{l}\text { Early } \\
\text { Gestation } \\
\text { Control Lungs }\end{array}$ & $\begin{array}{l}\text { Late } \\
\text { Gestation } \\
\text { Control Lungs }\end{array}$ & $\begin{array}{l}\text { Early } \\
\text { Gestation } \\
\text { Age BPD }\end{array}$ & $\begin{array}{l}\text { Late } \\
\text { Gestation } \\
\text { Age BPD }\end{array}$ & $\begin{array}{l}\text { WT HO Vs. RA } \\
\text { (BPD } \\
\text { equivalent) }\end{array}$ & $\begin{array}{l}\text { SK HO Vs. RA } \\
\text { (BPD } \\
\text { protection) }\end{array}$ & Gene function \\
\hline CD177 (CD177 Molecule) & $\downarrow$ & $\downarrow$ & $\downarrow$ & $\uparrow$ & $\uparrow 2.26378$ & $\uparrow 2.60461$ & $\begin{array}{l}\text { Neutrophil activation, } \\
\text { transmigration }\end{array}$ \\
\hline $\begin{array}{l}\text { ILIRL1(interleukin } 1 \\
\text { receptor like 1) }\end{array}$ & $\downarrow$ & $\downarrow$ & $\uparrow$ & $\uparrow$ & $\uparrow 1.5$ & No change & $\begin{array}{l}\text { Mediates cytokine-induced immune } \\
\text { and inflammatory responses. }\end{array}$ \\
\hline SFN (14-3-3 protein sigma) & $\downarrow$ & $\downarrow$ & $\uparrow$ & $\uparrow$ & $\uparrow 1.5$ & No change & $\begin{array}{l}\text { Promotes p53-regulated inhibitor } \\
\text { of G2/M progression }\end{array}$ \\
\hline $\begin{array}{l}\text { SH3RF2(SH3 Domain } \\
\text { Containing Ring Finger 2) }\end{array}$ & $\downarrow$ & $\downarrow$ & $\uparrow \uparrow$ & $\uparrow$ & $\uparrow \uparrow 4.8$ & $\uparrow 1.58$ & Protein ubiquitination \\
\hline $\begin{array}{l}\text { NNMT(Nicotinamide } \\
\text { N-Methyltransferase) }\end{array}$ & $\downarrow$ & $\downarrow$ & $\uparrow$ & $\uparrow$ & No change & $\downarrow 1.71$ & $\begin{array}{l}\mathrm{N} \text {-methylation of pyridines to } \\
\text { form pyridinium ions }\end{array}$ \\
\hline $\begin{array}{l}\text { LIPG (Lipase G, Endothelial } \\
\text { Type) }\end{array}$ & $\downarrow$ & $\uparrow$ & $\uparrow \uparrow$ & $\uparrow$ & No change & $\downarrow 3.29$ & $\begin{array}{l}\text { Molecular bridge between } \\
\text { endothelial cells and lipoproteins. }\end{array}$ \\
\hline SELE (Selectin- E) & $\downarrow \downarrow$ & $\downarrow$ & $\uparrow \uparrow$ & $\uparrow$ & $\uparrow 2.28$ & $\uparrow 1.3$ & $\begin{array}{l}\text { Recruits leukocytes to the site } \\
\text { of injury }\end{array}$ \\
\hline $\begin{array}{l}\text { ALDH1A3 (Aldehyde } \\
\text { Dehydrogenase } 1 \\
\text { Family Member A3) }\end{array}$ & $\downarrow \downarrow$ & $\downarrow \downarrow$ & $\uparrow \uparrow$ & $\uparrow$ & $\uparrow 1.9$ & $\uparrow 2.03$ & Detoxification of aldehydes \\
\hline $\begin{array}{l}\mathrm{CH} 25 \mathrm{H} \text { (Cholesterol } \\
\text { 25-Hydroxylase) }\end{array}$ & $\downarrow \downarrow$ & $\downarrow \downarrow$ & $\uparrow \uparrow$ & $\uparrow \uparrow$ & $\uparrow \uparrow 22.9$ & $\uparrow 1.6$ & $\begin{array}{l}\text { Catalyze the hydroxylation of } \\
\text { hydrophobic substrates. }\end{array}$ \\
\hline CXCL5 (CXCL5 or ENA78) & $\downarrow \downarrow$ & $\downarrow \downarrow$ & $\uparrow$ & $\uparrow \uparrow$ & $\uparrow 3.57$ & $\uparrow 3.26$ & $\begin{array}{l}\text { Recruit neutrophils, promote } \\
\text { angiogenesis and remodel } \\
\text { connective tissues }\end{array}$ \\
\hline $\begin{array}{l}\text { MARCO (macrophage } \\
\text { receptor with collagenous } \\
\text { structure) }\end{array}$ & $\downarrow \downarrow$ & $\downarrow$ & $\uparrow \uparrow$ & $\uparrow \uparrow$ & $\uparrow 2.18$ & $\uparrow 2.45$ & $\begin{array}{l}\text { Part of the innate antimicrobial } \\
\text { immune system }\end{array}$ \\
\hline
\end{tabular}


the lungs of BPD patients as well as in WT HO and Sphk $1^{-1-}$ HO groups, suggesting that these responses to hyperoxia were not mediated through SphK1. The fact that expression of murine genes Sh3rf2, Sele and Ch25h showed significant elevation in WT HO group compared to Sphk1 ${ }^{-/}$HO group suggests that the WT neonatal mice exposed to hyperoxia closely resemble human BPD. It is thus possible that these three genes could be mediated through SphK1/S1P pathway. In conclusion, the striking similarities in the differential expression of specific genes between human BPD and neonatal mice exposed to hyperoxia suggests that the neonatal mouse model investigated here resembles 'Early' gestation BPD.

\section{Conclusion}

In summary, this study provides the first ever genomewide analysis of differential expression in the lungs of neonatal BPD model as it relates to SphK1/S1P signaling. WT HO was associated with significantly increased expression of genes that promote apoptosis, retard cell multiplication, inflammation and extracellular matrix remodeling, whereas the Sphk $1^{-/-}$mice exposed to hyperoxia showed a downregulation of the corresponding genes. Interestingly, the differential gene regulation in our animal model of BPD shows similarity with 'Early' gestation BPD. Our study signifies potential role of SphK1/S1P signaling in the pathogenesis of BPD, and thereby makes an attractive therapeutic target for future drug development.

\section{Additional files}

Additional file 1: Table S1. Sequences of sybr green mouse primers used for RT-PCR. (DOCX $38 \mathrm{~kb}$ )

Additional file 2: Table S2. Top fifty enriched pathways are listed here by cluster. The process of clustering is explained in the materials and methods. (XLSX $20 \mathrm{~kb}$ )

Additional file 3: Table S3. Comparison of the 10 most highly differentiated genes between WT HO and Sphk $1^{-1-}$ HO groups. (XLSX $10 \mathrm{~kb}$ )

Additional file 4: Table S4. Comparison of the 10 most highly differentially expressed genes between WT RA and Sphk $1^{-1-}$ RA groups. (XLSX $9 \mathrm{~kb}$ )

Additional file 5: Table S5. Comparison of 10 most highly differentially expressed genes between Sphk $1^{-1-}$ RA and Sphk $1^{-1-}$ HO groups. (XLSX $31 \mathrm{~kb}$ )

Additional file 6: Table S6. Comparison of 10 most highly

differentiated genes between WT RA and WT HO groups. (XLSX 9 kb)

\section{Abbreviations}

ABC: ATP binding cassette; ANOVA: Analysis of variance; BAL: Bronchoalveolar lavage; BPD: Bronchopulmonary dysplasia; CDK: Cyclin dependent kinase; Cenp: Centromere protein; ECM: Extra cellular matrix; EGA: Estimated gestational age; FDR: False discovery rate; GADD: Growth arrest and DNA damage; HO: Hyperoxia; KO: Knockout; LPA: Lysophosphatidic acid; MCC: Mitotic checkpoint complex; NB: Newborn; NO: Normoxia; Nox: NADPH oxidase; PN: Postnatal; PW: Pathway; RA: Room air; ROS: Reactive oxygen species; RT-PCR: Real time polymerase chain reaction; S1P: Sphingosine-1- phosphate; S1P $1-5$ : S1P receptor 1 through 5; SphK: Sphingosine kinase; WT: Wild type

\section{Acknowledgements}

We acknowledge the comments from Roberto Machado, MD in shaping up the manuscript.

\section{Funding}

This work was supported by the University of Illinois at Chicago (UIC) Center for Clinical and Translational Science (CCTS) through Grant UL1TR000050 to A.H and by the National Institutes of Health Grant P01 HL98050 to V.N.The funding bodies financially supported the experiments involved in this research. The funding bodies did not play any role in the design of the study, collection, analysis, and interpretation of data or in the writing of the manuscript

\section{Availability of data and materials}

The microarray datasets supporting the conclusions of this article are available in the the National Center for Biotechnology Information Gene Expression Omnibus repository, with unique persistent identifier of NCBI tracking system accession number: 18,084,823, and hyperlink to the datasets is given below.

https://www.ncbi.nlm.nih.gov/geo/query/acc.cgi?acc=GSE87350

\section{Authors' contributions}

VN conceptualized the study and its design, interpreted results, edited and revised the manuscript. AWH performed experiments, interpreted results, prepared figures, edited and revised the manuscript. YD performed experiments and interpreted results. NMR analyzed data, interpreted results and prepared figures. DLE interpreted results, prepared figures, edited and revised the manuscript. PK interpreted results, edited and revised the manuscript. JUR interpreted results and conceptualized the study. SPR interpreted results and conceptualized the study. ZL analyzed data, interpreted results, prepared figures and drafted the manuscript. MMC analyzed data, interpreted results, prepared figures and drafted the manuscript. ZA analyzed data, interpreted results, prepared figures, drafted, edited and revised the manuscript. AH conceptualized the study and its design, performed experiments, analyzed data, interpreted results, drafted, edited and revised the manuscript. All authors read and approved the final manuscript.

\section{Ethics approval and consent to participate}

Not applicable as this is not a study involving human beings. All experiments using animals were approved by the Institutional Animal Care and Use Committee at the University of Illinois at Chicago (protocol \# 15-240). Sphk1 ${ }^{-1-}$ mice were obtained from Dr. Richard L. Proia (NIDDK, National Institutes of Health, Bethesda), and backcrossed to C57BL/6 background for two generations (F2 hybrid).Dr. Proia of National Institutes of health has gifted us the mice with permission to breed as approved by the Institutional Animal Care protocol.

\section{Consent for publication}

Not applicable.

\section{Competing interests}

The authors declare that they have no competing interests.

\section{Publisher's Note}

Springer Nature remains neutral with regard to jurisdictional claims in published maps and institutional affiliations.

\section{Author details}

${ }^{1}$ Departments of Medicine, University of Illinois, Chicago, IL 60612, USA. 2Department of Pharmacology, University of Illinois, Chicago, IL 60612, USA. ${ }^{3}$ Department of Biochemistry and Molecular genetics, University of Illinois, Chicago, IL 60612, USA. ${ }^{4}$ Department of Center for Research Informatics, University of Illinois at Chicago, Chicago, IL 60612, USA. ${ }^{5}$ Department of CoreGenomics Facility, University of Illinois, Chicago, IL 60612, USA. ${ }^{6}$ Department of Pediatrics, University of Illinois, Room \# 3140, COMRB Building, 909, South Wolcott Avenue, Chicago, IL 60612, USA. 
Received: 9 July 2017 Accepted: 10 August 2017 Published online: 29 August 2017

\section{References}

1. Farstad T, Bratlid D, Medbo S, Markestad T, Norwegian Extreme Prematurity Study G. Bronchopulmonary dysplasia - prevalence, severity and predictive factors in a national cohort of extremely premature infants. Acta Paediatr. 2011;100(1):53-8.

2. Landry JS, Menzies D. Occurrence and severity of bronchopulmonary dysplasia and respiratory distress syndrome after a preterm birth. Paediatr Child Health. 2011:16(7):399-403.

3. O'Reilly M, Sozo F, Harding R. Impact of preterm birth and bronchopulmonary dysplasia on the developing lung: long-term consequences for respiratory health. Clin Exp Pharmacol Physiol. 2013;40(11):765-73.

4. Trembath A, Laughon MM. Predictors of bronchopulmonary dysplasia. Clin Perinatol. 2012;39(3):585-601.

5. Vogel ER, Britt RD Jr, Trinidad MC, Faksh A, Martin RJ, MacFarlane PM, Pabelick CM, Prakash YS. Perinatal oxygen in the developing lung. Can J Physiol Pharmacol. 2015;93(2):119-27.

6. Berger J, Bhandari V. Animal models of bronchopulmonary dysplasia. The term mouse models. Am J Physiol Lung Cell Mol Physiol. 2014; 307(12):L936-47.

7. Bode C, Graler MH. Immune regulation by sphingosine 1-phosphate and its receptors. Arch Immunol Ther Exp. 2012;60(1):3-12.

8. Lai WQ, Wong WS, Leung BP. Sphingosine kinase and sphingosine 1phosphate in asthma. Biosci Rep. 2011;31(2):145-50.

9. Huang LS, Natarajan V. Sphingolipids in pulmonary fibrosis. Adv Biol Regul. 2015:57:55-63.

10. Chen J, Tang H, Sysol JR, Moreno-Vinasco L, Shioura KM, Chen T, Gorshkova I, Wang L, Huang LS, Usatyuk PV, et al. The sphingosine kinase 1/ sphingosine-1-phosphate pathway in pulmonary arterial hypertension. Am J Respir Crit Care Med. 2014;190(9):1032-43.

11. Xing XQ, Li YL, Zhang YX, Xiao Y, Li ZD, Liu LQ, Zhou YS, Zhang HY, Liu YH, Zhang LH, et al. Sphingosine kinase 1/sphingosine 1-phosphate signalling pathway as a potential therapeutic target of pulmonary hypertension. Int J Clin Exp Med. 2015:8(8):11930-5.

12. Natarajan V, Dudek SM, Jacobson JR, Moreno-Vinasco L, Huang LS, Abassi T, Mathew B, Zhao Y, Wang L, Bittman R, et al. Sphingosine-1-phosphate, FTY720, and sphingosine-1-phosphate receptors in the pathobiology of acute lung injury. Am J Respir Cell Mol Biol. 2013;49(1):6-17.

13. Harijith A, Pendyala S, Reddy NM, Bai T, Usatyuk PV, Berdyshev E, Gorshkova I, Huang LS, Mohan V, Garzon S, et al. Sphingosine kinase 1 deficiency confers protection against hyperoxia-induced bronchopulmonary dysplasia in a murine model: role of S1P signaling and Nox proteins. Am J Pathol. 2013;183(4):1169-82

14. Irizarry RA, Bolstad BM, Collin F, Cope LM, Hobbs B, Speed TP. Summaries of Affymetrix GeneChip probe level data. Nucleic Acids Res. 2003;31(4):e15.

15. Bolstad BM, Irizarry RA, Astrand M, Speed TP. A comparison of normalization methods for high density oligonucleotide array data based on variance and bias. Bioinformatics. 2003;19(2):185-93.

16. Irizarry RA, Hobbs B, Collin F, Beazer-Barclay YD, Antonellis KJ, Scherf U, Speed TP. Exploration, normalization, and summaries of high density oligonucleotide array probe level data. Biostatistics. 2003;4(2):249-64.

17. Eisenhart $C$. The assumptions underlying the analysis of variance. Biometrics. 1947;3(1):1-21.

18. Benjamini YYD. The control of the false discovery rate in multiple testing under dependency. Ann Stat. 2001;29(4):1165-88.

19. Foley EA, Kapoor TM. Microtubule attachment and spindle assembly checkpoint signalling at the kinetochore. Nat Rev Mol Cell Biol. 2013;14(1):25-37.

20. Varis A, Salmela AL, Kallio MJ. Cenp-F (mitosin) is more than a mitotic marker. Chromosoma. 2006;115(4):288-95.

21. Wood KW, Chua P, Sutton D, Jackson JR. Centromere-associated protein E: a motor that puts the brakes on the mitotic checkpoint. Clin Cancer Res. 2008;14(23):7588-92.

22. Perkowski S, Sun J, Singhal S, Santiago J, Leikauf GD, Albelda SM. Gene expression profiling of the early pulmonary response to hyperoxia in mice. Am J Respir Cell Mol Biol. 2003;28(6):682-96.

23. Staversky RJ, Vitiello PF, Gehen SC, Helt CE, Rahman A, Keng PC, O'Reilly MA. p21(Cip1/Waf1/Sdi1) protects against hyperoxia by maintaining expression of BCI-X(L). Free Radic Biol Med. 2006;41(4):601-9.
24. Vitiello PF, Staversky RJ, Gehen SC, Johnston CJ, Finkelstein JN, Wright TW, O'Reilly MA. p21Cip1 protection against hyperoxia requires BCl-XL and is uncoupled from its ability to suppress growth. Am J Pathol. 2006;168(6):1838-47.

25. Harijith A, Pendyala S, Ebenezer DL, Ha AW, Fu P, Wang YT, Ma K, Toth PT, Berdyshev EV, Kanteti P, et al. Hyperoxia-induced p47phox activation and ROS generation is mediated through S1P transporter Spns2, and S1P/ S1P1\&2 signaling axis in lung endothelium. Am J Physiol Lung Cell Mol Physiol. 2016;311(2):L337-51.

26. Bilodeau M, MacRae T, Gaboury L, Laverdure JP, Hardy MP, Mayotte N, Paradis V, Harton S, Perreault C, Sauvageau G. Analysis of blood stem cell activity and cystatin gene expression in a mouse model presenting a chromosomal deletion encompassing Csta and Stfa211. PLoS One. 2009;4(10):e7500.

27. Bhandari A, Carroll C, Bhandari V. BPD Following Preterm Birth: A Model for Chronic Lung Disease and a Substrate for ARDS in Childhood. Front Pediatr. 2016;4:60.

28. Nardiello C, Mizikova I, Morty RE. Looking ahead: where to next for animal models of bronchopulmonary dysplasia? Cell Tissue Res. 2017;367(3):457-68.

29. Ebenezer DL, Fu P, Natarajan V. Targeting sphingosine-1-phosphate signaling in lung diseases. Pharmacol Ther. 2016:168:143-57.

30. Szczepaniak WS, Zhang Y, Hagerty S, Crow MT, Kesari P, Garcia JG, Choi AM, Simon BA, McVerry BJ. Sphingosine 1-phosphate rescues canine LPSinduced acute lung injury and alters systemic inflammatory cytokine production in vivo. Transl Res. 2008;152(5):213-24.

31. Jolly PS, Rosenfeldt HM, Milstien S, Spiegel S. The roles of sphingosine-1phosphate in asthma. Mol Immunol. 2002;38(16-18):1239-45.

32. Price MM, Oskeritzian CA, Falanga YT, Harikumar KB, Allegood JC, Alvarez SE, Conrad D, Ryan JJ, Milstien S, Spiegel S. A specific sphingosine kinase 1 inhibitor attenuates airway hyperresponsiveness and inflammation in a mast cell-dependent murine model of allergic asthma. J Allergy Clin Immunol. 2013;131(2):501-11. e501

33. Subei AM, Cohen JA. Sphingosine 1-phosphate receptor modulators in multiple sclerosis. CNS Drugs. 2015;29(7):565-75.

34. Maceyka M, Sankala H, Hait NC, Le Stunff H, Liu H, Toman R, Collier C, Zhang M, Satin LS, Merrill AH Jr, et al. SphK1 and SphK2, sphingosine kinase isoenzymes with opposing functions in sphingolipid metabolism. J Biol Chem. 2005;280(44):37118-29.

35. Igarashi N, Okada T, Hayashi S, Fujita T, Jahangeer S, Nakamura S. Sphingosine kinase 2 is a nuclear protein and inhibits DNA synthesis. J Biol Chem. 2003;278(47):46832-9.

36. Kharel Y, Lee S, Snyder AH, Sheasley-O'neill SL, Morris MA, Setiady Y, Zhu R, Zigler MA, Burcin TL, Ley $K$, et al. Sphingosine kinase 2 is required for modulation of lymphocyte traffic by FTY720. J Biol Chem. 2005;280(44): 36865-72.

37. Takuwa Y, Du W, Qi X, Okamoto Y, Takuwa N, Yoshioka K. Roles of sphingosine-1-phosphate signaling in angiogenesis. World J Biol Chem. 2010;1(10):298-306.

38. Sugata N, Li S, Earnshaw WC, Yen TJ, Yoda K, Masumoto H, Munekata E, Warburton PE, Todokoro K. Human CENP-H multimers colocalize with CENP$\mathrm{A}$ and CENP-C at active centromere-kinetochore complexes. Hum Mol Genet. 2000;9(19):2919-26.

39. Testa JR, Zhou JY, Bell DW, Yen TJ. Chromosomal localization of the genes encoding the kinetochore proteins CENPE and CENPF to human chromosomes $4 \mathrm{q} 24->\mathrm{q} 25$ and $1 \mathrm{q} 32->\mathrm{q} 41$, respectively, by fluorescence in situ hybridization. Genomics. 1994;23(3):691-3.

40. Maiato H, Gomes AM, Sousa F, Barisic M. Mechanisms of Chromosome Congression during Mitosis. Biology (Basel). 2017;6(1):10-18.

41. Vitre B, Gudimchuk N, Borda R, Kim Y, Heuser JE, Cleveland DW, Grishchuk EL. Kinetochore-microtubule attachment throughout mitosis potentiated by the elongated stalk of the kinetochore kinesin CENP-E. Mol Biol Cell. 2014; 25(15):2272-81.

42. Meraldi P, Sorger PK. A dual role for Bub1 in the spindle checkpoint and chromosome congression. EMBO J. 2005;24(8):1621-33.

43. Londhe VA, Sundar IK, Lopez B, Maisonet TM, Yu Y, Aghai ZH, Rahman I. Hyperoxia impairs alveolar formation and induces senescence through decreased histone deacetylase activity and up-regulation of p21 in neonatal mouse lung. Pediatr Res. 2011;69(5 Pt 1):371-7.

44. O'Reilly MA. DNA damage and cell cycle checkpoints in hyperoxic lung injury: braking to facilitate repair. Am J Physiol Lung Cell Mol Physiol. 2001; 281(2):L291-305. 
45. O'Reilly MA, Staversky RJ, Finkelstein JN, Keng PC. Activation of the G2 cell cycle checkpoint enhances survival of epithelial cells exposed to hyperoxia. Am J Physiol Lung Cell Mol Physiol. 2003;284(2):L368-75.

46. Gartel AL, Tyner AL. The role of the cyclin-dependent kinase inhibitor p21 in apoptosis. Mol Cancer Ther. 2002;1(8):639-49.

47. De Langhe SP, Reynolds SD. Wnt signaling in lung organogenesis. Organ. 2008;4(2):100-8.

48. O'Reilly MA, Staversky RJ, Watkins RH, Maniscalco WM, Keng PC. p53independent induction of GADD45 and GADD153 in mouse lungs exposed to hyperoxia. Am J Physiol Lung Cell Mol Physiol. 2000;278(3):L552-9.

49. Kim R. Unknotting the roles of $\mathrm{BCl}-2$ and $\mathrm{BCl}-\mathrm{xL}$ in cell death. Biochem Biophys Res Commun. 2005;333(2):336-43.

50. Chen X, Walther FJ, Laghmani EH, Hoogeboom AM, Hogen-Esch AC, van Ark I, Folkerts G, Wagenaar GT. Adult Lysophosphatidic Acid Receptor 1Deficient Rats with Hyperoxia-Induced Neonatal Chronic Lung Disease Are Protected against Lipopolysaccharide-Induced Acute Lung Injury. Front Physiol. 2017:8:155.

51. Chen X, Walther FJ, van Boxtel R, Laghmani EH, Sengers RM, Folkerts G, DeRuiter MC, Cuppen E, Wagenaar GT. Deficiency or inhibition of lysophosphatidic acid receptor 1 protects against hyperoxia-induced lung injury in neonatal rats. Acta Physiol (Oxf). 2016;216(3):358-75.

52. Koo HC, Davis JM, Li Y, Hatzis D, Opsimos H, Pollack S, Strayer MS, Ballard PL, Kazzaz JA. Effects of transgene expression of superoxide dismutase and glutathione peroxidase on pulmonary epithelial cell growth in hyperoxia. Am J Physiol Lung Cell Mol Physiol. 2005;288(4):L718-26.

53. Rahman I, Mulier B, Gilmour PS, Watchorn T, Donaldson K, Jeffery PK, MacNee W. Oxidant-mediated lung epithelial cell tolerance: the role of intracellular glutathione and nuclear factor-kappaB. Biochem Pharmacol. 2001;62(6):787-94

54. Bhattacharya S, Go D, Krenitsky DL, Huyck HL, Solleti SK, Lunger VA, Metlay L, Srisuma S, Wert SE, Mariani TJ, et al. Genome-wide transcriptional profiling reveals connective tissue mast cell accumulation in bronchopulmonary dysplasia. Am J Respir Crit Care Med. 2012;186(4):349-58.

\section{Submit your next manuscript to BioMed Central and we will help you at every step:}

- We accept pre-submission inquiries

- Our selector tool helps you to find the most relevant journal

- We provide round the clock customer support

- Convenient online submission

- Thorough peer review

- Inclusion in PubMed and all major indexing services

- Maximum visibility for your research

Submit your manuscript at www.biomedcentral.com/submit 